\title{
A SIMPLE PORTABLE INSTRUMENT FOR THE ABSO- LUTE MEASUREMENT OF REFLECTION AND TRANSMISSION FACTORS
}

\author{
By A. H. Taylor
}

Early this year the author presented at the convention of the Optical Society of America a paper giving a brief review of the methods which had previously been used in measuring reflection factors, and describing a new type of absolute reflectometer. The complete description of that instrument, with the derivation of the theory, is now available in a scientific paper of this Bureau. ${ }^{1}$

The instrument described at that time was very thoroughly tested and was found to give correct results. However, certain precautions are necessary in its use and the mathematical equations are somewhat complex. These factors might tend to limit its use in the hands of inexperienced observers, though not necessarily so, as a calibration curve can be calculated and drawn for use in routine measurements.

One of the extremely interesting and important developments in that work was the high reflection factor obtained for magnesium carbonate. Measurements by four absolute methods gave an average factor of 99 per cent for a particular block of magnesium carbonate, whereas the previously accepted value was 88 per cent.

It has lately occurred to the author that a very simple reflectometer, based on one of the absolute methods employed in verifying the factor found for magnesium carbonate, could be constructed. It is the purpose of this paper to describe the new instrument, which is entirely different in principle from the one previously described.

\section{THEORY OF REFLECTOMETER}

If light is projected onto the inner wall of a small hollow sphere, painted with a diffusely reflecting white paint, it can be shown that the illumination of the surface by reflected light only will be equal in intensity at all points.

${ }^{1}$ B. S. Scientific Paper No. 39r. Also Journal of the Opt. Soc. of America, 4, January, rg2o. 
Let a small hollow sphere be arranged as shown in Fig. I. A small segment of the surface is cut away, leaving a hole over which the surface to be tested is placed. At another point on the sphere about $90^{\circ}$ from this one there is a small hole through which the opposite wall of the sphere is viewed by means of a portable photometer. The spot viewed is screened from the test surface by means of a small opaque screen.

Let $F=$ total light flux (lumens) entering the sphere.

$m=$ reflection factor of sphere surface.

$m^{\prime}=$ reflection factor of test surface.

$E^{\prime}=$ illumination of observation point when the direct light is projected onto the test surface.

$E=$ illumination of observation point when direct light is projected onto the sphere surface at a point unscreened from the observation point.

When the light is projected onto the test surface, it must be reflected from it and from the sphere wall once each before any of it can reach the observation point, since this spot is screened from the test surface. Hence the flux which is effective in illuminating the spot observed is $m^{\prime} m F$. In other words, the flux $F$, incident on the test surface, produces the same illumination of the observation spot as a point source of light placed at the center of the sphere and radiating $m^{\prime} m F$ lumens. When the incident beam is projected onto the sphere surface at a point unscreened from the spot observed, it is readily seen, by the same method of reasoning, that its effect on the observation spot is the same as that of a point source radiating $m F$ lumens. Hence in each case the illumination of the spot is directly proportional to these flux values, and the ratio of the illumination in the two cases is the reflection factor of the test surface. Therefore

$$
\frac{E^{\prime}}{E}=\frac{m^{\prime} m F}{m F}=m^{\prime}
$$

It is to be noted here that no assumption has been made in regard to the way in which the light flux is reflected from the test surface. Hence the reflection factor of the test surface will be correctly evaluated no matter how the flux reflected from the test surface is distributed over the sphere wall. Also, the reflection factor measured is the factor for light of the color delivered by the lamp and is unaffected by selective reflection by the sphere walls. 


\section{DETAILS OF CONSTRUCTION}

The details of the instrument constructed are shown in Fig. I. The hollow sphere used was a spun copper ball, 5 inches in diameter, such as is used with steam float valves. The lighting tube, which is set at an angle to the sphere surface, can be rotated about an axis normal to the surface of the sphere. This allows the direct light to be thrown on the test surface or the sphere wall as may be desired, the angle of incidence being

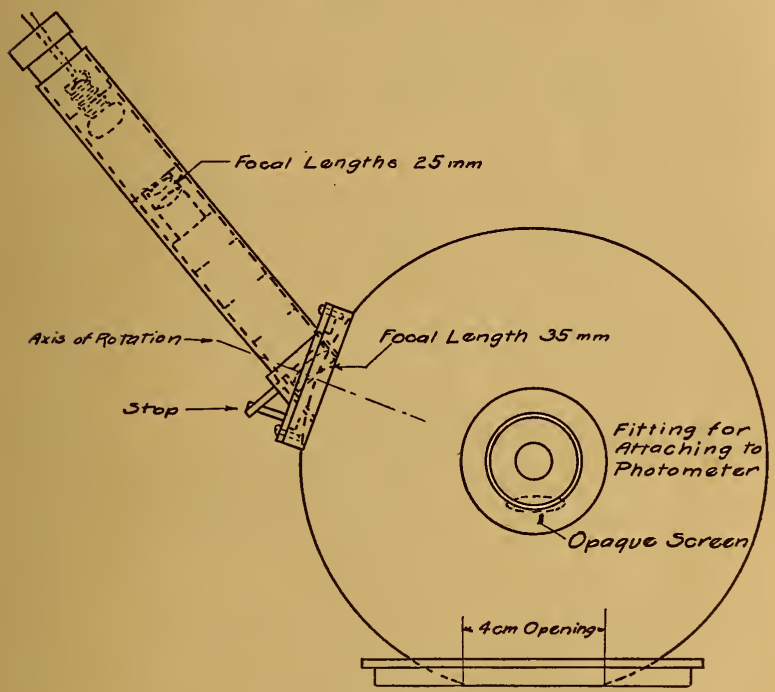

FIG. I. $\rightarrow$ Sketch of instrument without photometer

about $40^{\circ}$ from the normal. By means of a good lens system a narrow beam of light, without scattered light, is obtained. This results in a fairly uniform sharply defined spot of light about 2.0 $\mathrm{cm}$ in diameter, so that the opening over which the test surface is placed need not be very large. A 2.8-volt opal-back flashlight lamp is used in the tube.

The particular instrument used in these tests was designed and built to be used with a Macbeth illuminometer. A lens of $6 \mathbf{I}$ $\mathrm{mm}$ focal length inserted in the elbow tube of the illuminometer 


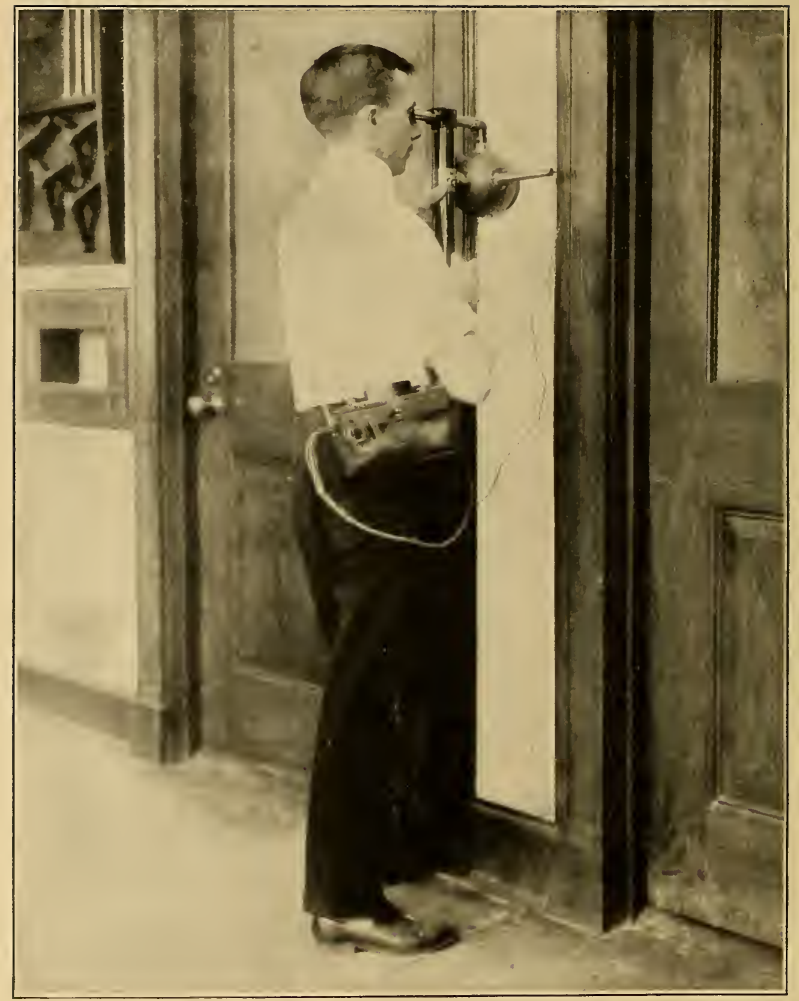

FIG. 2.-Method of using instrument to measure the reflection factor of a wall 
restricts the spot observed to a diameter of about $4 \mathrm{~mm}$, and hence a very small screen can be used to screen this spot from the test surface.

\section{EXPERIMENTAL WORK}

In order to verify the results obtained with the reflectometer previously described, a graded series of test objects was made up. Neutral gray objects were obtained by mixing black drawing ink and lampblack with a white cement (Keene's Fine). They were surfaced with coarse sandpaper, resulting in fairly good diffusers. These surfaces were tested for reflection factors by observation of surface brightness at intervals of $10^{\circ}$, using the apparatus shown in Fig. 3. The amount of flux reflected was calculated from these

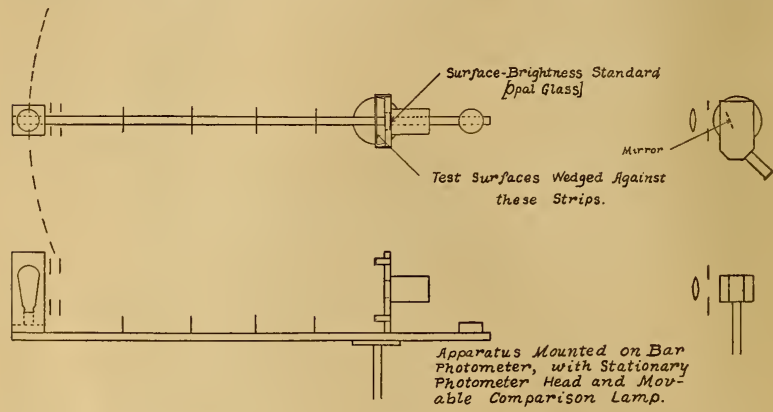

FIG. 3.-Apparatus used in determining reflection factors by measurements of surface brightness at $10^{\circ}$ intervals

observations, and since the incident flux was known, the ratio of the reflected to the incident flux gave the reflection factors. These test objects were restandardized and used in verifying the results given by the new reflectometer. To these were added a block of magnesium carbonate previously tested, a polished sheet of milk glass, and a white cardboard painted with the same paint as that used in an 88-inch integrating sphere. The reflection factor of this paint had been previously determined by measuring the total illumination of the sphere wall when a lamp of known candlepower was burned in the sphere.

The tests of the cement surfaces with the first type of reflectometer (described in Scientific Paper No. 391), when used in the way recommended, showed that its results were in almost perfect agreement with those obtained by the point-by-point method. 
The results of the measurements with the new type reflectometer described above are shown in Table $\mathrm{I}$.

TABLE 1.-Reflection Factors by Two Methods of Measurement

\begin{tabular}{|c|c|c|c|c|c|}
\hline \multirow[b]{2}{*}{ Test object } & \multicolumn{2}{|c|}{ Rfflection factor } & \multirow[b]{2}{*}{ Test object } & \multicolumn{2}{|c|}{ Reflection factor } \\
\hline & $\begin{array}{c}\text { Point- } \\
\text { by-point } \\
\text { method }\end{array}$ & $\begin{array}{l}\text { New type } \\
\text { reflec- } \\
\text { tometer }\end{array}$ & & $\begin{array}{c}\text { Point- } \\
\text { by-point } \\
\text { method }\end{array}$ & $\begin{array}{l}\text { New type } \\
\text { reflec- } \\
\text { tometer }\end{array}$ \\
\hline & Per cent & Per cent & & Per cent & Per cent \\
\hline Cement Standard No. $1 .$. & 18.5 & 19.2 & Cement Standard No. $6 \ldots \ldots$ & 82.3 & 81.3 \\
\hline Cement Standard No. $2 \ldots$ & 38.4 & 39.3 & Cement Standard No. $7 \ldots \ldots$ & 86.6 & 86.4 \\
\hline Cement Standard No. $3 . .$. & 43.2 & 43.2 & Polished milk glass....... & 76.2 & 76.4 \\
\hline Cement Standard No. 4 ....... & 60.4 & 60.5 & Sphere paint............ & $a 94.0$ & 93.9 \\
\hline Cement Standard No. 5 ...... & 67.8 & 68.1 & Magnesium carbonate... & b 99.0 & 98.5 \\
\hline
\end{tabular}

$a$ Value obtained by measurement of total illumination in 88 -inch sphere when a lamp of knowu candlepower was burned in the sphere.

${ }^{b}$ Average of all previous measurements by four absolute methods, including the point-by-point method.

Such differences as exist in the above table may very easily be experimental errors. For all practical purposes the two methods may be considered to be in perfect agreement.

In using the instrument, no accurate voltage adjustment of the lamps in the photometer and the reflectometer is necessary, as both operate from the same battery. If only approximate factors are desired, the voltages can be adjusted so that the photometer reads ro when the light is directed onto the sphere wall, and then the reading when the light is directed onto the test surface is onetenth of the percentage reflection factor. This eliminates the necessity for any computations.

\section{USE OF INSTRUMENT FOR MEASUREMENT OF TRANSMISSION FACTORS}

By the addition of an exterior light source, giving a concentrated beam of the proper intensity, the same instrument may be used to measure transmission factors of clear or diffusing media. In the laboratory such a light source is easily obtained by proper screening of a lamp with reflector. For precision work the method of procedure would be as follows:

I. Turn the reflectometer lighting tube to project its beam onto the sphere wall at a point unscreened from the photometer observation point, then read the photometer.

2. Place over the opening in the sphere the substance to be tested for transmission, and again read the photometer. Then extinguish the lamp in the lighting tube.

3. Project the beam from the exterior lighting source through the large opening in the sphere and make a photometer reading. 
4. Leaving the exterior lighting source unchanged, place over the opening the substance to be tested, and again read the photometer.

Let the photometer reading (in brightness or illumination units) in the four cases be respectively $a, b, c$, and $d$. Then the transmission-factor of the substance is $\frac{a d}{b c}$.

In using the instrument in this way the exterior light source should produce a beam which is somewhat smaller in diameter than the hole where it enters the sphere in order that when the substance to be tested is in place the light diffused by the substance at the edges of the beam will not escape around the edges of the hole.

This method of measuring transmission factors is similar in principle to that employed by Luckiesh and Mellor, ${ }^{2}$ but the apparatus and test procedure are different. Transmission factors for diffused illumination might be determined by illuminating the test substance by means of a diffusing hemisphere, as in the method used by Luckiesh and Mellor.

\section{CONCLUSION}

Only one adaptation of the principle of this instrument has been shown, but there is no reason why it could not be adapted for use with almost any good type of portable photometer.

There is a considerable advantage in using an absolute instrument of this type rather than an instrument giving relative values, since no standard surface is required, and it is not necessary for lamps or sphere surface to remain constant from day to day.

The use of a low-voltage flashlight lamp in the lighting tube makes the instrument easily portable and convenient. A further improvement as regards portability would be to eliminate the battery-meter set and substitute therefor a large three-cell flashlight battery and miniature resistances.

The use of the instrument for measuring both reflection and transmission factors doubles its usefulness. No other instrument having this dual value has been proposed.

This instrument gives further proof of the very high reflection factor of magnesium carbonate, and establishes the value of 99 per cent for a particular block beyond much doubt.

WASHINGTON, October 22, 1920.

2 Measurement of Transmission Factors, by M. Luckiesh and L. L. Mellor, Jour. Franklin Inst., 186, p. 529, October, 1928; also Jour. Optical Soc, of America, 2 and 3, January-March, rgrg. 